\title{
RIPGUT BROME (BROMUS DIANDRUS) DISTRIBUTION IN RELATION TO TOPOGRAPHY AND MANAGEMENT ON SEVEN HIGH COUNTRY PROPERTIES IN THE SOUTH ISLAND
}

\author{
K.N. TOZER, A.J. MARSHALL, J.R. SEDCOLE and G.R. EDWARDS \\ Agriculture Group, Agriculture and Life Sciences Division, PO Box 84, Lincoln \\ University, 7647 Lincoln, New Zealand \\ Corresponding author: tozerk@lincoln.ac.nz
}

\begin{abstract}
Seeds of ripgut brome, an annual grass, can contaminate the wool, pelt and carcasses of sheep grazing on high country properties. The distribution of ripgut brome on seven high country properties in Marlborough, Canterbury and Otago was determined during December 2006 to February 2007. The presence of ripgut brome was measured in paddocks of different management intensities at altitudes ranging from 400 to $1400 \mathrm{~m}$. Ripgut brome grass presence was lower in sites managed less intensively (e.g. less fertiliser and oversowing), in hard than laxly grazed sites, and in sites of high exotic perennial grass cover. It was more prevalent on stock camps than off stock camps and on steeper slopes and sunny aspects but was unaffected by legume cover, shrub presence or altitude. The results suggest that increased grazing intensity and enhanced plant competition are methods that may be used to suppress ripgut brome on hill and high country properties.
\end{abstract}

Keywords: Bromus diandrus, grazing, hill country, mitigation, ripgut brome, weed control.

\section{INTRODUCTION}

Ripgut brome (Bromus diandrus Roth), an annual grass originating from the Mediterranean region, is an invasive weed on many arable and dryland livestock properties and in waste places in the South and North Islands of New Zealand (Edgar \& Connor 2000). On arable farms ripgut brome can reduce wheat and barley yields, and herbicide programmes have been developed for the weed's control (Dastgheib et al. 2003). In hill and high country pastures, ripgut brome seeds $(1.5-2.5 \mathrm{~cm})$ can contaminate wool, pelts and carcasses of sheep. However, for these properties control methods are less well developed.

The distribution and biology of annual grass weeds relative to grazing intensity, fertiliser and plant competition is important as these are factors that farmers may consider manipulating to control weeds (Hancock \& Schuster 2004). For example, increasing perennial grasses competition can reduce invasion of some annual grasses (Tozer et al. 2007). Previous studies show that increased grazing pressure can reduce ripgut brome incidence in extensively grazed rangelands by reducing seed production and enhancing the growth of more grazing tolerant species (Biswell 1956).

This study analysed the distribution of ripgut brome within 32 paddocks on seven high country Merino properties in Marlborough, Canterbury and Central Otago. At each site, the presence of ripgut brome was related to grazing intensity, fertiliser and oversowing history, and topography. The results of the study are used to suggest how grazing management and plant competition may be used to control ripgut brome in grazed hill and high country pastures. 


\section{MATERIALS AND METHODS}

A study was conducted between December 2006 and February 2007 to determine variables associated with ripgut brome distribution within paddocks on seven Merino grazing, hill/high country farms where ripgut brome was known to be present on the farm. The properties were in Tarras valley, and near Hawea and Twizel (Otago, n=3), Mid and North Canterbury $(\mathrm{n}=2)$, and in the Awatere Valley (Marlborough, $\mathrm{n}=2$ ).

On each property, farmers identified paddocks with management intensity of (1) low: oversowing and $\mathrm{S}$ and $\mathrm{P}$ fertiliser within the last 20 years, areas grazed infrequently; (2) moderate: oversowing and S and P fertiliser application within the last 5 years, areas grazed with moderate frequency; or (3) high: oversowing and $\mathrm{S}$ and $\mathrm{P}$ fertiliser application within the last 5 years, areas grazed most frequently. The percentage cover of ripgut brome was measured in 3-9 paddocks per farm, representative of these management intensities. The cover of ripgut brome (flowering and vegetative), shrubs, perennial grasses (not including native tussocks), legumes and tussocks, was assessed in three $5 \times 5 \mathrm{~m}$ quadrats laid out at random intervals along $350 \mathrm{~m}$ transects positioned in the top, middle and bottom of the slope in each paddock. A total of 213 quadrats was surveyed. For each quadrat, management intensity (as described above), local grazing intensity at the time of the study as indicated by pasture height (lax: $>10 \mathrm{~cm}$, intense: $<10 \mathrm{~cm}$, assessed visually), presence of stock camp, angle of the slope of quadrat to the nearest $5^{\circ}$, altitude $(\mathrm{m})$ and aspect (sunny: NW to NE, moderate sun: NE to SE combined with SW to NW, and shady: SE to SW) were recorded. Transects ranged from $400 \mathrm{~m}$ to $1400 \mathrm{~m}$ in altitude.

The presence or absence of ripgut brome in each quadrat was used as the response variable in fitting a multiple logistic regression model using generalized linear models (Crawley 1993). A binomial probability distribution with a logit link function was specified. A maximal model using 10 predictor variables was constructed. The minimum adequate model was found by deleting variables with no significant effect from the maximal model, which left those factors whose deletion significantly reduced the goodness-of-fit of the model $\left(\chi^{2}\right)$. At all stages, control of the model was manual.

\section{RESULTS}

There were six significant predictor variables in the model (Table 1). Four variables, $\%$ tussock, \% herbaceous legume, presence of shrubs and altitude, had no significant effect $(\mathrm{P}>0.05)$ on ripgut brome presence and were deleted from the model.

TABLE 1: Deviance for predictor variables in the minimum adequate model for ripgut brome presence.

\begin{tabular}{lccc}
\hline Predictor variable & df & Deviance $\left(\chi^{2}\right)$ & $\mathrm{P}$ \\
\hline Management intensity & 2 & 13.3 & 0.001 \\
Grazing intensity & 1 & 11.1 & $<0.001$ \\
Aspect & 2 & 8.8 & 0.014 \\
Stock camp & 1 & 5.2 & 0.02 \\
Slope & 1 & 5.5 & 0.02 \\
$\%$ perennial grasses & 1 & 14.1 & $<0.001$ \\
Residual & 204 & 236.7 & \\
\hline
\end{tabular}

Ripgut brome presence was lowest under low management intensity, intermediate under high management intensity and greatest under moderate management intensity (Fig. 1a). Aggregating high and moderate management intensity into a single factor showed no significant difference between these levels $\left(\chi^{2}=0.1\right.$, df $\left.=1, P>0.05\right)$. Ripgut brome presence was higher with lax than intense grazing (Fig. 1b) and on than off stock camps (Fig. 1c). The presence of ripgut brome was higher in sunny than shady aspects 
(Fig. 1d), but there was no significant difference between moderately sunny and sunny aspects (aggregation into a single factor $\chi^{2}=0.55, \mathrm{df}=1, \mathrm{P}>0.05$ ). The presence of ripgut brome declined with increasing perennial grass cover (Fig. 2a) and increased with slope steepness (Fig. 2b).
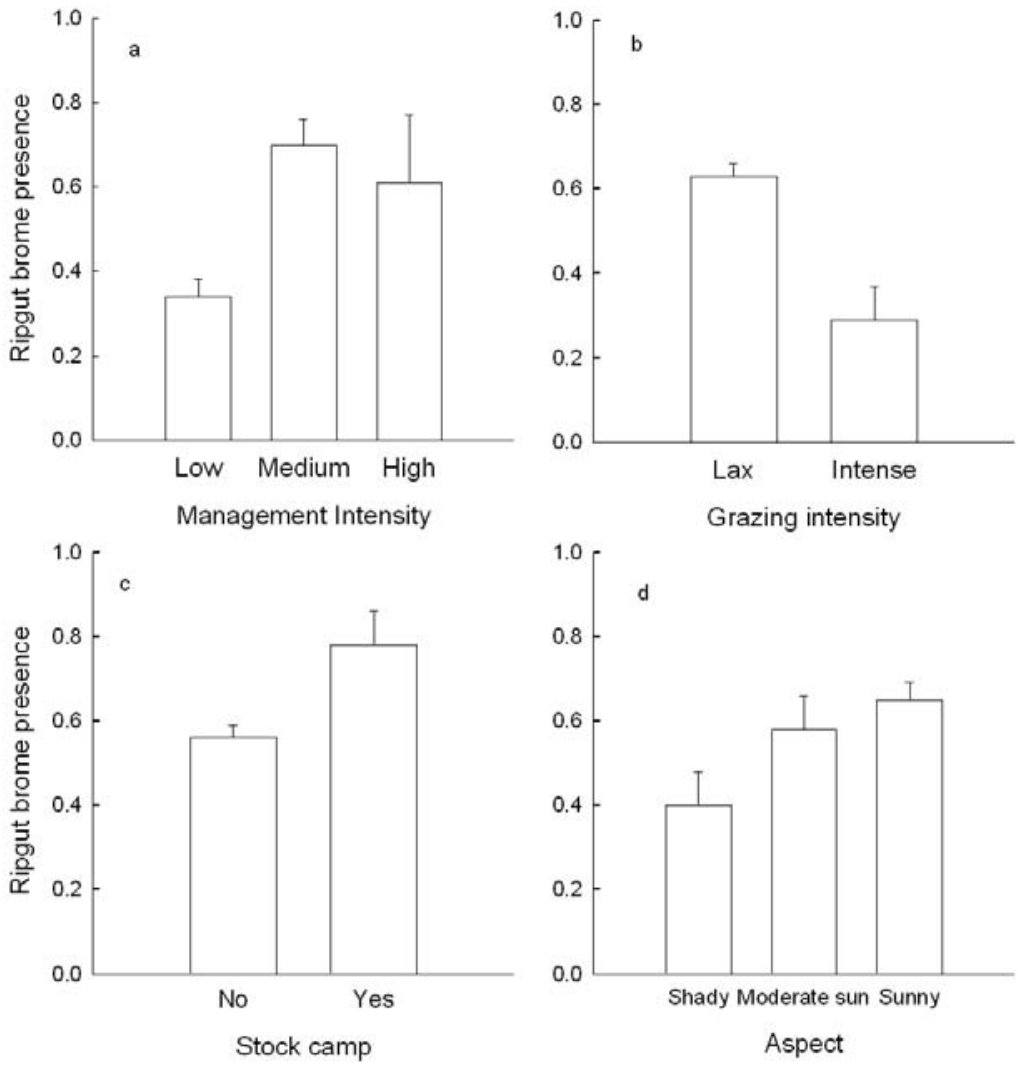

FIGURE 1: The predicted mean proportion (+SE) of quadrats where ripgut brome was present under four significant variables (a) management intensity, (b) grazing intensity, (c) stock camp presence and (d) aspect. 

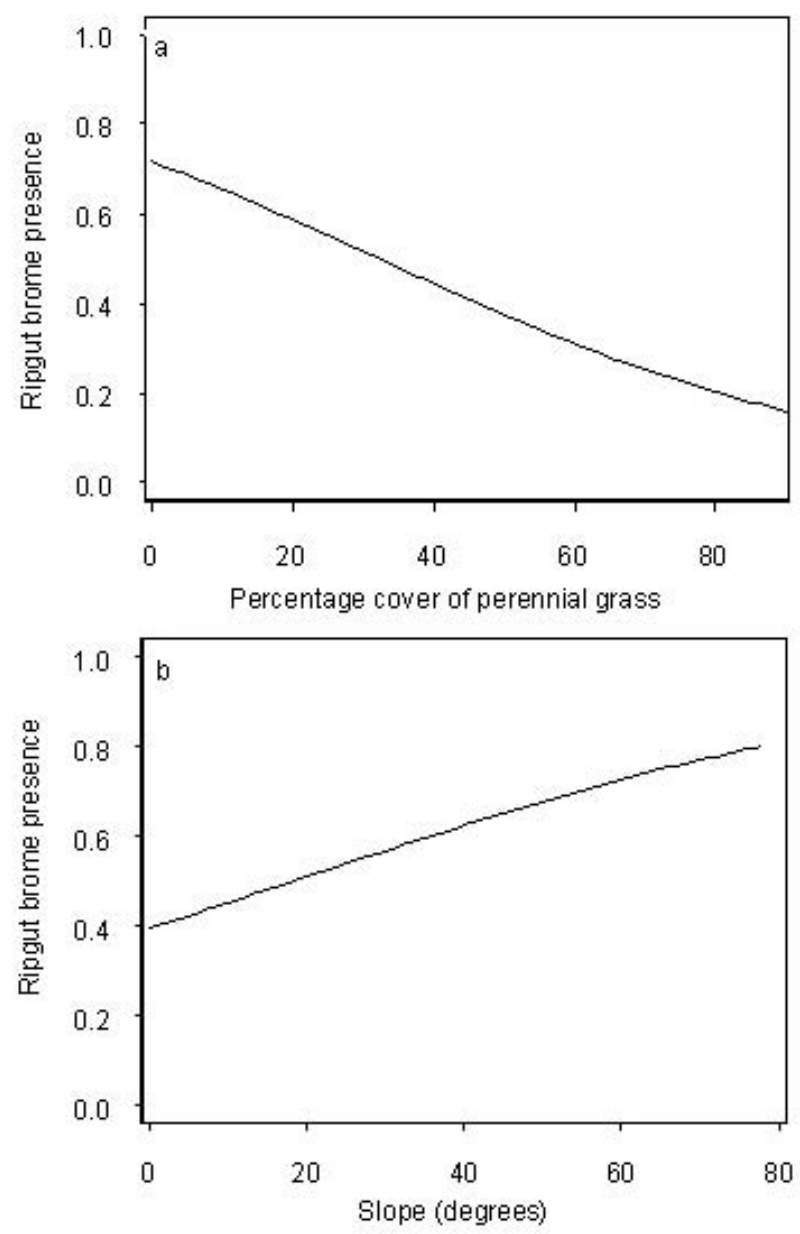

FIGURE 2: The predicted mean proportion of quadrats where ripgut brome was present in relation to (a) percentage perennial grass (not including native tussocks) and (b) slope. The lines represent predicted values for the relationship between ripgut brome presence and perennial grass or slope back-transformed from the logit scale.

\section{DISCUSSION}

Local grazing pressure was a highly significant predictor variable in the model, with a reduced presence of ripgut brome in intensively grazed areas. The observed relationship with local grazing intensity is consistent with a previous study in Californian annual grassland noting that ripgut brome increased when sheep grazing was excluded (Robinson \& Quinn 1988). Furthermore, Rosiere (1987) reported that increasing the grazing intensity of sheep reduced ripgut brome content more than that of barley grass 
(Hordeum spp.) in Californian woodlands. These results suggest that increasing grazing intensity, but not overgrazing so as to create soil disturbance and sites for establishment, may be a potential control strategy. However, it is not clear at what stage of the ripgut brome lifecycle (seedlings, flowering plants or seedhead) more intense grazing needs to be targeted to suppress the weed. This aspect is currently being investigated. The increased presence with lax grazing also points towards increased ripgut brome spread within and between paddocks in years of high pasture supply and undergrazing (e.g. a wet spring like in 2006).

The sites on each farm designated as low management intensity had a lower presence of ripgut brome compared to sites managed more intensively (e.g. more oversowing, fertiliser and grazing). This result may reflect that these sites were more resistant to invasion, either because the suite of species present excluded invading species or because there were few establishment microsites due to low grazing pressure and disturbance (Edwards et al. 2005). Alternatively, it may reflect a lack of ripgut brome propagules (e.g. seed-limitation) as dispersal to the site through sheep and human activities is low. Visual observations indicated that ripgut brome dominated in highly disturbed sites, such as along farm vehicle tracks, indicating a potential pathway of entry into remote sites. Seed sowing studies are underway to test factors (e.g. seed, disturbance and competition) that may limit recruitment in the different sites.

The presence of ripgut brome was greater on than off stock camps. The result might be due to greater ripgut brome seed dispersal (e.g. on sheep) to these sites of high livestock use, and that nutrient and dung input, and treading damage, occasionally create bare patches within the vegetation that would be ideal establishment microsites. Barley grass, another annual weed grass, also often occurs on stock camps, which may be due to its ability to avoid the high salinity (i.e. soluble salts such as $\mathrm{K}^{+}, \mathrm{Ca}^{+}, \mathrm{HCO}_{3}^{-}, \mathrm{NO}_{3}^{-}$) found on stock camps in summer (Popay \& Sanders 1982). Ripgut brome presence may be greater on stock camps for the same reason.

Topography had a marked effect on the presence of ripgut brome, with a higher presence on sunny than shady aspects and on steep than shallow slopes. Sunny (north facing), steeper slopes typically have higher soil temperatures, are drier and have higher evapotranspiration rates than shady, sheltered slopes (White 1990). Ripgut brome may be well suited to these sites as it can withstand periods of moisture stress and completes its life-cycle more rapidly under dry conditions (Burghardt \& Froud-Williams 1996).

There was little influence of altitude on ripgut brome, demonstrating its ability to grow in the range of environmental extremes within the $400 \mathrm{~m}$ to $1400 \mathrm{~m}$ altitude zone and that thermal time at high altitude (e.g. Power et al. 2006) is sufficient for ripgut brome's rapid lifecycle. Previous research has shown that shrubs may facilitate invasion of grasses by providing establishment microsites, and by protecting the plant from grazing (Rebollo et al. 2002). However, there was no impact of shrub cover on ripgut brome presence on the farms studied. This may be due to overall lax spring grazing on most properties and the tall open structure of the shrubs (e.g. matagouri) in the sites studied, which allowed easier access for livestock.

In conclusion, this study points towards increased livestock grazing pressure and competition from perennial grasses being potential strategies for reducing ripgut brome on hill and high country farms. Current research is underway to determine whether this can be achieved by targeted salt $(\mathrm{NaCl})$ application to slopes in order to enhance grazing preference and intensity (Gillespie et al. 2006). Salt application in late autumn and early spring in combination with oversowing of perennial grasses and legumes is currently being tested as a control measure in parts of paddocks dominated by ripgut brome.

\section{ACKNOWLEDGEMENTS}

We thank the property owners for their assistance and participation in this project. Funding for this research is provided by: MAF Sustainable Farming Fund, Meat \& Wool New Zealand, Merino NZ Inc., Lincoln University Research Fund, The Struthers Trust and the Argyle Trust. 


\section{REFERENCES}

Biswell HH 1956. Ecology of California grasslands. Journal of Range Management 9:19-24.

Burghardt G, Froud-Williams RJ 1996. Effect of water stress and temperature on growth, transpiration and stomatal frequency in Bromus sterilis and B. diandrus. Aspects of Applied Biology 45: 219-226.

Crawley MJ 1993. GLIM for Ecologists. Blackwell Science, Oxford, UK. 379 pp.

Dastgheib F, Rolston MP, Archie WJ 2003. Chemical control of brome grasses (Bromus spp.) in cereals. New Zealand Plant Protection 56: 227-232.

Edwards GR, Hay MJM, Brock JL 2005. Seedling recruitment dynamics of forage and weed species under continuous and rotational sheep grazing in a temperate New Zealand pasture. Grass and Forage Science 60: 186-199.

Edgar E, Connor HE 2000. Flora of New Zealand Volume 5: Grasses. Manaaki Whenua Press, Lincoln, New Zealand. 650 pp.

Gillespie BJ, Lucas RJ, Moot DJ, Edwards GR 2006. Can topdressing with salt increase oversowing success and pasture quality on steep, south facing slopes in hill country pastures? Proceedings of the New Zealand Grassland Association 68: 349-353.

Hancock B, Schuster H 2004. Winning against seeds. Management tools for your sheep enterprise. Meat \& Livestock Australia Ltd, Sydney, Australia. 44 pp.

Popay AI, Sanders P 1982. Seasonal variations in salinity of soils supporting different levels of barley grass (Hordeum murinum L.). New Zealand Journal of Agricultural Research 25: 223-227.

Power DR, Pollock KM, Lucas RJ, Moot DJ 2006. Clover species cover on summer dry hill country in Central Otago. Proceedings of the New Zealand Grassland Association 68: 343-347.

Rebollo S, Milchunas DG, Noy-Meir I, Chapman PL 2002. The role of spiny plant refuge in structuring grazed shortgrass steppe plant communities. Oikos 98: 53-64.

Robinson GR, Quinn JF 1988. Extinction, turnover and species diversity in an experimentally fragmented California annual grassland. Oecologia 76: 71-82.

Rosiere RE 1987. An evaluation of grazing intensity influences on California annual range. Journal of Range Management 40: 160-165.

Tozer KN, Ates S, Mapp NR, Smith MC, Lucas RJ, Edwards GR 2007. Effects of the MAX P endophyte in tall fescue on pasture production and composition, and sheep grazing preference, in a dryland environment. Proceedings of the 6th International Symposium on Fungal Endophytes of Grasses. Pp. 259-262.

White JGH 1990. Hill and high country pasture. In: Langer RHM ed. Pastures: their ecology and management. Oxford University Press, Auckland. Pp. 299-336. 